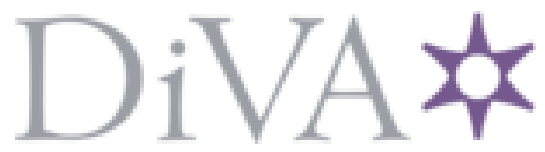

http://www.diva-portal.org

This is the published version of a paper presented at 11th International Symposium on Visual Information Communication and Interaction (VINCI '18), 13-15 August 2018, Växjö, Sweden.

Citation for the original published paper:

Fagerholm, A-S., Andersson, M. (2018)

Information Visualization and Design

In: Karsten Klein, Yi-Na Li, and Andreas Kerren (ed.), VINCI '18 Proceedings of the 11th International Symposium on Visual Information Communication and Interaction (pp. 112-113). New York: ACM Publications

https://doi.org/10.1145/3231622.3231636

N.B. When citing this work, cite the original published paper.

Permanent link to this version:

http://urn.kb.se/resolve?urn=urn:nbn:se:miun:diva-35031 


\section{Information Visualization and Design}

\author{
Anna-Sara Fagerholm \\ Department of Design \\ Mid Sweden University \\ Sweden \\ anna-sara.fagerholm@miun.se
}

\author{
Mattias Andersson \\ Department of Design \\ Mid Sweden University \\ Sweden \\ mattias.andersson@miun.se
}

\begin{abstract}
Recently, there has been an increase of data visualizations and in the diversity of forms. In parallel, design research has developed over the last decades. However, there have been few academic publications in the area of design specifically focusing on visualization research. In this poster, we present an overview of design research within the field of visualization in order to investigate key research areas and possible directions for future work.
\end{abstract}

\section{KEYWORDS}

visualization, design, visual thinking, user-centered design

ACM Reference Format:

Anna-Sara Fagerholm and Mattias Andersson. 2018. Information Visualization and Design. In Proceedings of the 11th International Symposium on Visual Information Communication and Interaction (VINCI '18), Växjö, Sweden, August 13-15, 2018. ACM, New York, NY, USA, 2 pages. https: //doi.org/10.1145/3231622.3231636

\section{INTRODUCTION}

Today, visualizations are available to many people to view, analyze and to make decision upon, often used to give a comprehensible overview of large and complex amounts of data [9, 19]. Recently, the necessity and number of applications of data visualizations have grown dramatically and consequently, so has the diversity of forms $[11,18]$. However, not all visualizations provide effective ways of communicating in terms of usability and usefulness $[8,9,13]$. Moreover, problems associated with the validity and reliability have been reported [7]. Visual literacy, the ability to use, interpret and critically examine visual material, is essential in all visually oriented disciplines [16]. The most essential steps in the visualization process is the encoding of data into visual elements by the designer and the decoding of visual elements back into the data in the mind of the reader [4]. In accordance, researchers argue that visualization developers are engaged in the design process [13].

\section{METHODOLOGY}

This study is based on a scoping of literature published in journals of design and visualization between 2000 and 2017. This scoping study comprises a further type of literature review with the intent to identify research gaps by reviewing existing literature [1]. The

Permission to make digital or hard copies of part or all of this work for personal or classroom use is granted without fee provided that copies are not made or distributed for profit or commercial advantage and that copies bear this notice and the full citation on the first page. Copyrights for third-party components of this work must be honored.

For all other uses, contact the owner/author(s).

VINCI '18, August 13-15, 2018, Växjö, Sweden

(c) 2018 Copyright held by the owner/author(s).

ACM ISBN 978-1-4503-6501-7/18/08.

https://doi.org/10.1145/3231622.3231636 scoping study is based on two steps: 1) searching for literature on visualization and design using search topic design, and 2) searching for literature on following keywords central to the research field of design; usability, evaluation and user experience using search topic visualization. Search tool used is Primo and search sources are electronic databases. Articles excluded are studies that tend to tackle design within the field of visualization without connecting to visual theoretical assumptions or design theories. However, instances where different design practices or skills were used in information visualization research were identified as this might point towards future areas for design research.

Table 1: Search strategy scoping review in two steps

\begin{tabular}{|l|l|l|}
\hline Scoping review & Step 1 & Step 2 \\
\hline Keywords & $\begin{array}{l}\text { Visualization } \\
+ \text { Design }\end{array}$ & $\begin{array}{l}\text { Usability, } \\
\text { Evaluation, } \\
\text { User Experience }\end{array}$ \\
\hline Search topic & Design & Visualization \\
\hline Search period & $2000-2017$ & $2000-2017$ \\
\hline
\end{tabular}

\section{RESULTS AND DISCUSSION}

\subsection{Design within the field of visualization}

This section is a presentation of themes of design in visualization research found in the scoping review. The first theme is the visual view, mainly focusing on aesthetics. For example, the attractiveness of graph designs in visualizations are investigated and the findings shows that attractiveness judgements are affected by perceived ease of use of the graphs [15]. Here, design is important in the development of visualizations [6]. Researchers are critical to visualizations that present little guidance to the reader [6]. The scoping review also indicate a cognitive view related to storytelling. Visualization is a cognitive support for users and the way they perceive visualizations can influence their understanding of data [17]. Visualization must be seen as a process that combine art and science [2]. In addition, the presentation of visualizations using elements from storytelling should be the next logical step in research [10]. The transforming of data into visually stories should consist of 1) exploration of data, 2) making a story, and 3) telling a story [12]. Also, the results indicate a usability view. Here, researchers have reported on the problems of measuring insights of visualizations $[3,5,14]$.

\section{CONCLUSIONS}

There is a gap of visual knowledge in the research field of visualization. This visual knowledge-gap arises from a lack of design 
competence in the visualization process and an absence of evaluation methods. The scoping review conducted indicates the necessity of design research in three key areas: user-centered design, visual thinking and visual storytelling.

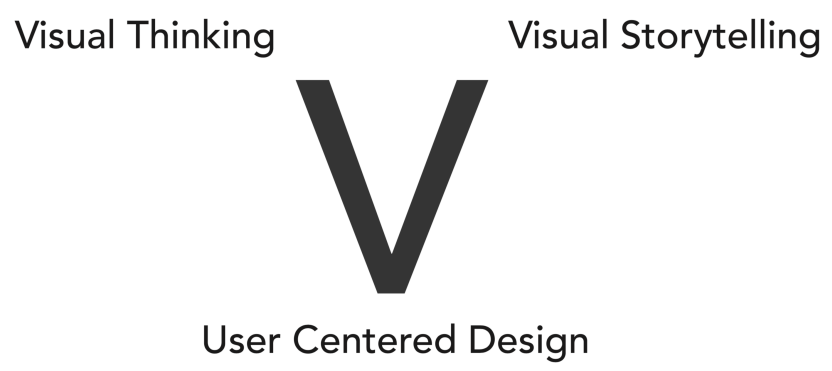

Figure 1: Key areas where design is required in visualization research.

This study shows that user-centered design could be an essential part in the visualization development. Design thinking through a design methodology have the potential to result in a clearly articulated process. Reading and understanding data is about human perception and cognition, and therefore, we firstly argue that this method could be beneficial in the developing process of visualizations. Secondly, we argue that we need new evaluation methods that attempt to measure insights of visualizations more directly. Hence, this points towards a potentially interesting research field in developing fast and reliable evaluation methods for visualization inspired by design methodology. Also, we find visual thinking being a relevant approach of design research in the field of visualization as visual thinking is an active problem- solving process that begins with perception and relies on the visual language of images, patterns, shapes, symbols and colors [20]. Visual thinking can help us to understand what we "read" in visualizations and how others "read" them. Therefore, the framework of design principles should be involved in the research field of visualization. Finally, visual storytelling is identified as a key area where design is required in visualization research. Not only the exploring and making in visualization is of importance, but also the telling. An essential part in making a visual story is design knowledge. This study indicates that the visual representations of design decisions are fundamental in any visualization process. Here, researchers can focus on design skills and manipulation of perception and cognition by advocating principles of design. This will prove even more crucial as visualization is increasingly used for decision-making. In conclusion, the Visualization $V$ intends to bring an interdisciplinary approach to the research field. Here, design is more than information aesthetics, it is an essential dimension for visual communication supporting cognitive insights.

\section{ACKNOWLEDGMENTS}

This work was supported by Mid Sweden University and the Municipality of Sundsvall, Sweden.

\section{REFERENCES}

[1] Hilary Arksey and Lisa O'Malley. 2005. Scoping Studies: Towards a Methodological Framework. International fournal of Social Research Methodology 8, 1 (2005), 19-32. https://doi.org/10.1080/1364557032000119616

[2] André G.P. Brown. 2003. Visualization as a Common Design Language: Connecting Art and Science. Automation in Construction 12, 6 (2003), 703-713. https://doi.org/10.1016/S0926-5805(03)00044-X

[3] Eva R. Brumberger. 2007. Making the Strange Familiar: A Pedagogical Exploration of Visual Thinking. Journal of Business and Technical Communication 21, 4 (2007), 376-401. https://doi.org/10.1177/1050651907304021

[4] Alberto Cairo. 2012. The Functional Art: An Introduction to Information Graphics and Visualization. New Riders.

[5] Remco Chang, Caroline Ziemkiewicz, Tera Marie Green, and William Ribarsky. 2009. Defining Insight for Visual Analytics. IEEE Computer Graphics and Applications 29, 2 (March 2009), 14-17. https://doi.org/10.1109/MCG.2009.22

[6] Russell Chun. 2017. Redundant Encoding in Data Visualizations: Assessing Perceptual Accuracy and Speed. Visual Communication Quarterly 24, 3 (2017), 135-148. https://doi.org/10.1080/15551393.2017.1343153

[7] Johanna Drucker. 2011. Humanities Approaches to Graphical Display. Digital Humanities Quarterly 5, 1, Article 2 (2011). http://digitalhumanities.org/dhq/vol/ 5/1/000091/000091.html

[8] Fabiola Cristina RodrÃnguez Estrada and Lloyd Spencer Davis. 2015. Improving Visual Communication of Science through the Incorporation of Graphic Design Theories and Practices into Science Communication. Science Communication 37, 1 (2015), 140-148. https://doi.org/10.1177/1075547014562914

[9] Petra Isenberg, Niklas Elmqvist, Jean Scholtz, Daniel Cernea, Kwan-Liu Ma, and Hans Hagen. 2011. Collaborative Visualization: Definition, Challenges, and Research Agenda. Information Visualization 10, 4 (2011), 310-326. https: //doi.org/10.1177/1473871611412817

[10] Robert Kosara and Jock Mackinlay. 2013. Storytelling: The Next Step for Visualization. Computer 46, 5 (May 2013), 44-50. https://doi.org/10.1109/MC.2013.36

[11] Kostiantyn Kucher, Carita Paradis, and Andreas Kerren. 2018. The State of the Art in Sentiment Visualization. Computer Graphics Forum 37, 1 (Feb. 2018), 71-96. https://doi.org/10.1111/cgf.13217

[12] Bongshin Lee, Nathalie Henry Riche, Petra Isenberg, and Sheelagh Carpendale. 2015. More Than Telling a Story: Transforming Data into Visually Shared Stories. IEEE Computer Graphics and Applications 35, 5 (Sept. 2015), 84-90. https://doi. org/10.1109/MCG.2015.99

[13] Andrew Vande Moere and Helen Purchase. 2011. On the Role of Design in Information Visualization. Information Visualization 10, 4 (2011), 356-371. https: //doi.org/10.1177/1473871611415996

[14] Chris North. 2006. Toward Measuring Visualization Insight. IEEE Computer Graphics and Applications 26, 3 (May 2006), 6-9. https://doi.org/10.1109/MCG. 2006.70

[15] Annemarie Quispel, Alfons Maes, and Joost Schilperoord. 2016. Graph and Chart Aesthetics for Experts and Laymen in Design: The Role of Familiarity and Perceived Ease of Use. Information Visualization 15, 3 (2016), 238-252. https://doi.org/10.1177/1473871615606478

[16] Anne Morgan Spalter and Andries van Dam. 2008. Digital Visual Literacy. Theory Into Practice 47, 2 (2008), 93-101. https://doi.org/10.1080/00405840801992256

[17] Melanie Tory and Torsten Möller. 2004. Human Factors in Visualization Research. IEEE Transactions on Visualization and Computer Graphics 10, 1 (Jan. 2004), 72-84. https://doi.org/10.1109/TVCG.2004.1260759

[18] José Luis Valero Sancho, Jordi Català Domínguez, and Beatriz Elena Marín Ochoa. 2014. An Approach to the Taxonomy of Data Visualisation. Revista Latina de Comunicación Social 69 (2014), 486-507. https://doi.org/10.4185/RLCS-2014-1021en

[19] Colin Ware. 2012. Information Visualization: Perception for Design (3rd ed.). Elsevier Science. https://doi.org/10.1016/C2009-0-62432-6 